\title{
A criação do mundo e outras belas histórias indígenas *
}

Arquivo recebido em 23 de outubro de 2011 e aprovado em 15 de novembro de 2011

V. 1 - N. 2 -

$2^{\circ}$ Semestre de 2011

* Resenha do livro organizado por: SOUZA,

Emerson Oliveira \& PREZIA, Benedito Antônio Genofre, Editora Formato/ Saraiva, São Paulo, 2011.

\section{Resumo}

Esta coletânea deseja apresentar aos jovens brasileiros não apenas a sabedoria indígena, mas também a religiosidade e a beleza poética desses povos, geralmente desconhecidas. Contou também com a recuperação da memória familiar de um dos organizadores, que é da etnia Guarani.

Palavras chaves: literatura, índio, sabedoria indígena, religião indígena.

\section{Resumé}

Ce recueil veux présenter aux jeunes brésiliens pas seulement la sagesse indiènne, mais aussi la religiosité et la beauté poétique de ces peuples, en général assez inconnus. Il récupère aussi partie la mémoire familialle d'un des organisateurs, qui appartient à l'éthnie guarani.

Mots-clés: littérature, indiens, des savoirs autochtones, la religion indigène.

\section{Sobre os organizadores:}

EMERSON OLIVEIRA SOUZA, Guarani Nhandeva, formado em Ciências 
Sociais pela Pontifícia Universidade Católica de São Paulo, Programa Pindorama e representante dos indígenas da cidade de São Paulo junto ao Comitê Regional da Funai - Coordenação Regional do Litoral Sudeste-SP.

BENEDITO ANTONIO GENOFRE PREZIA, mestre em Linguística Geral pela USP, doutor em Antropologia pela PUC-SP, autor de vários livros paradidáticos sobre a temática indígena e coordenador do Programa Pindorama para indígenas da PUC-SP.

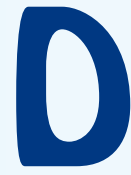

urante muito tempo os indígenas das Américas foram vistos como selvagens, bárbaros, atrasados. Sua religião era feitiçaria e suas histórias sagradas, lendas.

Isto se pode ver pelos escassos textos recolhidos por missionários e cronistas portugueses da época colonial brasileira. Com exceção de alguns jesuítas, a memória indígena do Brasil, sobretudo Tupinambá, foi preservada graças, sobretudo, aos cronistas franceses dos séculos XVI e XVII. Convém destacar os trabalhos do frade capuchinho André Thevet ([1558], 1978; [1575] 2009]), que viveu no Rio de Janeiro, por ocasião da fracassada colônia da França Antártica, que durou um pouco mais de uma década Igualmente importantes foram os relatos dos frades Claude d'Abbeville ([c.1616] 1975) e Yves d'Évreux ([c.1616] 2009), que viveram na ilha do Maranhão, por ocasião da França Equinocial. Parte dos manuscritos deste último foi parar no lixo, quando sua obra poderia atrapalhar a alianças que se delineava entre as coroas francesas e espanholas, após a expulsão francesa (MARCEL, G. Introd., In: D’EVREUX, 2009: 71).

No México o descaso e a repressão religiosa levaram para a fogueira muitos sábios e escritos aztecas e maias, tidos como idolátricos, embora parte tenha sido salva por obra de alguns intelectuais espanhóis e mecenas italianos (GARCIA, L. La represión religiosa..., Civilización: configura- 
ciones de la diversidad, México: CADAL, 1983:11-35). Assim chegaram até nós vários códices e textos como Popol Vuh (2007), que pôde nos dar uma idéia do avanço cultural desses povos. No Peru, devido a uma geração mestiça, muita coisa se conservou, embora seja pouco conhecida de nosso público (ver MOLINA, Cristóbal de, o Cuzquenho ([1575]1916) ou VEGA, Garcilaso de la, [1609] 1988).

A partir do final do século XIX houve um despertar para essas culturas, vistas ainda com o olhar europeu, que buscava entendê-las. Suas tradições e relatos eram classificados como "pensamento selvagem", que pouca coisa tinha a acrescentar à cultura ocidental, atraindo os pesquisadores mais pelo exotismo do que por seu valor próprio.

Somente mais tarde, na metade do século XX, o grande antropólogo Lévi-Strauss lançou um livro, chamado justamente $O$ pensamento selvagem, que fez com que as tradições e mitos desses povos fossem reconhecidos na sua real dimensão, alcançando um patamar de cidadania frente à cultura ocidental ([1962] 1989).

Hoje, a dimensão poética começa também a ser desvendada, pelo fato que de que essas culturas estão sendo mais conhecidas. De fato, essa poética milenar, não apenas dos povos de culturas urbanas da América -- Maias, Astecas e Incas --, como também a de povos de cultura ágrafa, começam a ser estudadas e publicadas, inclusive no Brasil. Basta ver a recente obra Popol Vuh (2007), o livro sagrado maia, cujo texto integral foi lançado aqui, acompanhado de alguns estudos literários sobre o poema. Não se podem esquecer a coletânea de textos dos Guarani Mbyá do Paraguai, sobretudo os coletados por Leon Cadogan, Ayvu Rapyta (1997), e a coletânea coletada e comentada por Pierre Clastres, intitulado A fala sagrada (Papirus, 1990). O mais recente trabalho sobre mitos tupis, analisados sob a ótica literária, foi há pouco lançado por Alberto Mussa, Meu destino é ser onça (Record, 2009). 
A proposta de nossa publicação foi de colocar em evidência o viés literário e religioso desses povos, para que fossem mais divulgados textos de grande valor, que até agora eram praticamente esquecidos, embora muitos deles já tenham sido publicados.

Emerson buscou também junto à sua família Guarani relatos míticos e cantos que ouviu na infância, mostrando quão importante e urgente é fazer este resgate, antes que eles desapareçam, frente à pressão cultural de nossa sociedade.

Escolhemos relatos e textos não apenas de indígenas do Brasil, como também de outras partes da América, recolhendo depoimentos recentes e antigos, que fazem parte do acervo cultural de nosso continente.

Nosso propósito primordial foi mostrar o lirismo e a sabedoria desses povos, independente de sua região de origem, já que a beleza perpassa textos elaborados pelos Inuit, do Alaska, até escritos do povo Mapuche da Argentina. Segue abaixo um pequeno poema de Uvarnuk, xamã Inuit:

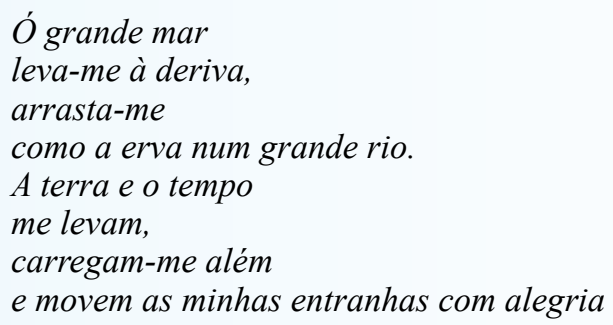

(In: MCLUHAN, T.C., 1996: 26).

Não podemos esquecer de nossos poetas indígenas, como Lourenço Rondon (Cibae Ewroro), do povo Bororo, falecido precocemente em 2002. Ao apresentar os depoimentos dos participantes das três primeiras Assembléias de Chefes Indígenas, realizadas na década de 1970, assim se exprimiu: $O$ homem branco, aquele que se diz civilizado, pisou duro não só na terra, mas na alma de meu povo, e os rios cresceram e o mar se tornou mais salgado porque as lágrimas da minha gente foram muitas 
(Revista Vozes, n. 3, ano 70, 1976, p. 195).

Quisemos também inserir alguns textos no original, para que o leitor brasileiro pudesse também ter contato com as línguas indígenas, como este poema quéchua, do século XVI, Cantiga de amor, recolhido por Gacilaso de la Vega:

Caylla llapi

Puñunqui.

Chaupituta,

Samusac.

Ao som da cantiga

dormirás.

À meia noite,

eu virei.

(VEGA, Garcilaso de la. 1988: I, 116)

Uma cantiga guarani nhandeva, recolhida pelo autor do livro Emerson Souza, junto à sua mãe, Ernestina Kunhã Nimuendu, foi igualmente inserida.

Anhã aminoé,

Tapeguasupe Kurusu.

Tangará rapé

Patuá minae, kakaju...

Lá vem o Anhã ${ }^{1}$, no cruzamento da estrada grande.

Um tangará pelo caminho, com um patuá no peito, vai gritando...

Deixamos um grande espaço às falas religiosas, colocando textos míticos e preces de vários povos, como esta bênção da moradia, do povo Cheroki

$$
\begin{gathered}
\text { Que os ventos suaves do céu soprem } \\
\text { docemente sobre esta casa } \\
\text { e que o Grande Espirito } \\
\text { abençoe a todos que entram aqui. }
\end{gathered}
$$

Inserimos também falas de denúncia sobre a destruição da natureza, como a famosa carta do cacique Seatle, e textos de sabedoria mostrando

1. Anhã, entidade ambivalente, identificada geralmente como espírito maléfico. 
a visão de mundo desses povos tradicionais, não só de lideranças antigas, como também uma reflexão de Nailton Muniz, do povo Pataxó Hã-hã-hãe.

Apesar de termos separado os textos por seções, criando uma específica para os poemas, todos eles, indistintamente, apresentam grande beleza poética.

Infelizmente muitos relatos não puderam ser aqui inseridos, devido às limitações de direitos autorais. Mas esperamos, que com esta coletânea o público brasileiro possa ter contato com este rico acervo de nossa cultura ancestral, valorizando-o e levando-o não apenas para os cursos de literatura e ecologia, mas para todos os cursos e público em geral.

Benedito Prezia \& Emerson Guarani

\section{Bibliografia}

BROTHERSTON, Gordon \& MEDEIROS, Sérgio (org.). Popol Vuh. São Paulo: Iluminuras, 2007. Ed. bilingue.

CADOGAN, León (org.). Ayvu Rapyta. Textos míticos de los Mbyá-Guarani del Guairá. Asunción: CEADUC/CEPAG, 1997. Ed. bilingue.

CHILAN BALAN. El Libro de los Libros de Chilam Balam. In: LEÓN PORTILLA, M. A conquista da América Latina vista pelos índios. Petrópolis: Vozes, 1984, p.59-60.

CIMI. Outros 500, construindo uma nova história. São Paulo: Salesiana, 2001.

CLASTRES, Pierre. A fala sagrada. Mitos e cantos sagrados dos índios Guarani. Campinas: Papirus, 1990.

D’ABBEVILLE, Claude. História da missão dos Padres Capuchinhos na Ilha do Maranhão e terras circunvizinhas. [c. 1616]. Belo Horizonte: Itatiaia; São Paulo: Edusp, 1975. (Col. Reconquista do Brasil, v. 19).

D'ÉVREUX, Pe. Yves. História das coisas memoráveis, ocorridas no Maranhão nos anos de 1613 e 1614 [c.1616]. Rio de Janeiro: Fundação Darcy Ribeiro; Ed. Batel, 2009. (Col. Franceses no Brasil, v. IV).

LEVI-STRAUSS, Claude. O pensamento selvagem. Campinas: Papirus, 1989. 
MCLUHAN, T.C. Pés nus sobre a terra sagrada. Porto Alegre: L\&PM, 1996.

MOLINA, Cristóbal de, (El Cusqueño). Relación de las Fábulas y Ritos de los Incas [1575]. Lima: Librerria San Marti, 1916.

MUSSA, Alberto. Meu destino é ser onça. Rio de Janeiro: Record, 2009.

RONDON, Eugênio, A voz dos que não tinham voz. In: Revista de Cultura Vozes, n. 3, ano 70, 1976.

THEVET, André. As singularidades da França Antártica. [1558]. Belo Horizonte: Itatiaia; São Paulo: Edusp, 1978. (Col. Reconquista do Brasil, v. 45) . A Cosmografia Universal de André Thevet, cosmógrafo do rei [1575]. Rio de Janeiro: Fundação Darcy Ribeiro; Ed. Batel, 2009. (Col. Franceses no Brasil, v. II).

VEGA, Garcilaso de la. Comentarios reales, 1609. Lima: Editorial Mercúrio, 1988, 3 v. 